\title{
Anxiety levels and health-related quality of life in parents of children with different types of physical disabilities
}

\author{
DOI: https://doi.org/10.5114/pq.2020.102158
}

\author{
Hatice Adiguzel ${ }^{1 \oplus}$, Nevin Ergun $^{2 \oplus}$, Bulent Elbasan ${ }^{3 \oplus}$ \\ ${ }^{1}$ Department of Physiotherapy and Rehabilitation, Faculty of Health Sciences, Kahramanmaras Sutcu Imam University, \\ Kahramanmaras, Turkey \\ ${ }^{2}$ Department of Physiotherapy and Rehabilitation, Faculty of Health Sciences, SANKO University, Gaziantep, Turkey \\ ${ }^{3}$ Department of Physiotherapy and Rehabilitation, Faculty of Health Sciences, Gazi University, Ankara, Turkey
}

\section{Abstract}

Introduction. Disability has negative effects on families' psychological health and quality of life. This study aimed to investigate the anxiety level and quality of life of parents having children with different physical disabilities, such as spina bifida, muscular dystrophy, cerebral palsy, and Down syndrome, and compare them with those of healthy children's parents.

Methods. Health status and anxiety level of the parents were assessed by the Nottingham Health Profile (NHP) and State-Trait Anxiety Inventory (STAI-I and STAI-II). The impact on the parents and level of the children's functional independence were evaluated by the Turkish version of the Impact on Family Scale (IPFAM) and Functional Independence Measure for Children. Functional activities of the children were assessed by the Pediatric Evaluation of Disability Inventory (PEDI).

Results. A statistically significant difference was found between the control group and the parents having children with disabilities in terms of IPFAM and PEDI functional skills $(p<0.05)$. There was a statistically significant difference between the IPFAM total scores of the disabled children and their healthy peers $(p<0.001)$.

Conclusions. The impact on the families with physically disabled children did not change with the diagnosis type. A difference was observed between the parents of children with different physical disabilities and those of healthy children. Also, the functional skills of the children with disabilities were negatively affected compared with their healthy peers. Health-related quality of life of the families was influenced by the independence level of the children in daily living activities.

Key words: children with disabilities, anxiety, parents, quality of life

\section{Introduction}

Disability is a life-long condition involving different carerelated needs and many psychosocial problems [1]. Effects of disabled children's health on families' psychological health and life quality are inevitable. It has been shown that families with disabled children are exposed to chronic stress, have communication problems, experience social isolation, and have to spend extra time on the care of their children. Parents of children with mental/physical disabilities are more stressed and have higher anxiety levels than those having children with no disabilities [2-5]. Since the activity limitations, participation restrictions, and social and physical barriers are different in each disability group, impacts on parents may also be different $[3,6]$. Especially the mothers of physically disabled children present more depression symptoms depending on the children's functional levels. In addition, a positive relationship between the time spent on the care of the child with a disability and the strain levels of the caregivers has been shown. As the time spent on care may vary in different types of disabilities, families' levels of strain and anxiety may also be different $[5,7,8]$. As a result, they may experience limitations in achieving the rehabilitation goals of their children, which suggests that, in addition to the physiotherapy applied in physically disabled individuals, rehabilitation services need to consider identifying and meeting the social needs of these parents. Studies have emphasized that more research with a control group is required to determine the effect of caring for a child with cerebral palsy (CP) on parents' functionality and welfare $[3,6]$. However, there exists no study in the literature examining these parents' anxiety levels, the extent to which these families are affected by the disease, and their health-related quality of life, and also providing comparisons with healthy children's parents. Therefore, this study was planned to investigate the quality of life, anxiety levels, the impact levels of the disease, and the social effect of the disease in parents of children with different types of physical disabilities, and to compare them with those of healthy children's parents.

\section{Subjects and methods}

\section{Subjects}

The study was conducted with the parents of 69 physically disabled (CP, spina bifida [SB]: myelomeningocele, muscular dystrophy [MD], or Down syndrome [DS]) individuals treated at Gazi University Pediatric Rehabilitation Unit and Special Education and Rehabilitation Centre, and 22 healthy controls. Parents of physically disabled or healthy children aged 4-20 years, without any known functional or psychological problems, who volunteered and signed an informed written consent form, and who were literate were included in the study. Parents of children with multiple disabilities or severe/moderate mental impairment were not included in the study.

Correspondence address: Hatice Adiguzel, Department of Physiotherapy and Rehabilitation, Faculty of Health Sciences, Kahramanmaras Sutcu Imam University, 46100, Dulkadiroglu, Kahramanmaras, Turkey, e-mail: fzthatis@gmail.com, https://orcid.org/0000-0001-9323-839X 


\section{Study procedures}

Children's and parents' demographic data (age, height, weight, educational level) were recorded. Furthermore, the parents were examined with the Impact on Family Scale (IPFAM), State Anxiety Inventory (STAI-I)/Trait Anxiety Inventory (STAI-II), Nottingham Health Profile (NHP), Functional Independence Measure for Children (WeeFIM), and Pediatric Evaluation of Disability Inventory (PEDI).

IPFAM (Turkish version) was used to measure the effect of the burden on parents. IPFAM is a 33-item inventory taking approximately 10-15 minutes to complete. Each item is scored between 4 (strongly agree) and 1 (strongly disagree); 27 items measure the general impact on the family and 6 items measure the impact of the disabled child on the siblings. IPFAM subscales refer to overall impact, disruption of social relations, coping, and financial impact. Low scores indicate low impact [9].

The parents' anxiety levels were evaluated by STAI-I and STAI-II. This is a self-report questionnaire measuring familial stress. The questionnaire consists of 2 subscales of 20 items each and each item is rated on a 4-point scale. It is a wellstructured clinical tool to assess the current state of anxiety (STAI-I) and anxiety tendency (STAI-II). The cut-off value is $39-40$, indicating that the level of anxiety is clinically significant [10].

The parents' health-related quality of life was assessed by NHP [12]. NHP has 38 yes/no items and is a subjective tool measuring health status by evaluating distress in 6 subgroups, namely, physical activity (8), pain (8), sleep (5), emotional reactions (9), social isolation (5), and energy (3). The score for each subgroup is between 0 (no problem) and 100 (there is a problem in the entire list) [11].

WeeFIM for children is a short and comprehensive measurement tool determining the developmental, educational, and social functional limitations of children with CP or other developmental disorders [9]. It is used to assess the child's level of functional independence in 6 areas related to daily living activities. The tool subdomains include self-care (6 items), sphincter control (2), mobility (3), locomotion (2), communication (2), and social cognition (3). Each item is scored between 1 (total dependence) and 7 (total independence). The total score range is $18-126$.

The Turkish version of PEDI was used to detect the presence, severity, and area of the functional delay in children. PEDI has 3 scales: functional skills (197 items), caregiver assistance (20), and modifications (20). Personal care is represented by 73 items, mobility by 59 items, and social function by 65 items. Higher scores indicate better functionality [12].

The tests were administered via face-to-face interviews by the researcher-in-charge or the parents filled out the questionnaire by themselves after the items were explained to them in the rehabilitation centre in which their children were treated, on the day of treatment. The tests take 30-45 minutes when implemented via face-to-face interviews, and 25-30 minutes if the parents fill them out by themselves.

\section{Statistical analysis}

The data were analysed by using the SPSS 25.0 software. Mean \pm standard deviation and median (min-max) values were provided as descriptive statistics. Normality of the data was evaluated with the Kolmogorov-Smirnov test. One-way ANOVA and the Kruskal-Wallis variance analysis were used for normally distributed data and non-normally distributed data in group comparisons, respectively. Regard- ing binary comparisons, Tukey's test was applied for ANOVA and the Mann-Whitney $U$ test was used for the Kruskal-Wallis analysis of variance. Bonferroni corrected $p$ value was considered in the Mann-Whitney $U$ test, with statistical significance set at $p<0.005$. Elsewhere, $p<0.05$ was considered statistically significant.

\section{Ethical approval}

The research related to human use has complied with all the relevant national regulations and institutional policies, has followed the tenets of the Declaration of Helsinki, and has been approved by the Gazi University Ethics Committee (\#2017-272). Clinical trial number: NCT04035967.

\section{Informed consent}

Informed consent has been obtained from all disabled children's parents included in this study.

\section{Results}

The parents' mean age was $38.6 \pm 6.4$ years (min-max: $31-52$ ). Overall, $91.2 \%$ of the parents were mothers and $8.8 \%$ were fathers. Their educational level was primary school in $37.4 \%(n=34)$, high school in $25.3 \%(n=23)$, university in $18.7 \%(n=17) ; 6.6 \%$ had no education.

The distribution of the parents depending on the children's disability type was as follows: $18.7 \%$ SB $(n=17), 19.8 \%$ MD $(n=18), 17.6 \%$ DS $(n=16), 19.8 \%$ CP $(n=18)$, and $24.2 \%$ controls $(n=22)$. A total of $52.75 \%$ of the children were females $(n=48)$ and $47.25 \%$ were males $(n=43)$. The mean age of the children was $6.47 \pm 2.47$ years (min-max: $4-12$ ) for $\mathrm{SB}, 11.69 \pm 4.96$ years (min-max: 4-20) for MD, $5.87 \pm 2.44$ years (min-max: $2-10$ ) for DS, $8.83 \pm 4.25$ years (min-max: 4-18) for $C P$, and $11.31 \pm 4.28$ years (min-max: $5-18)$ for controls. The children's mean height was $103.58 \pm 13.44 \mathrm{~cm}$ (min-max: 80-135) for SB, $136.05 \pm 25.02 \mathrm{~cm}$ (min-max: 98-170) for MD, $101.75 \pm 22.69 \mathrm{~cm}$ (min-max: 55-30) for DS, $122.94 \pm 19.93 \mathrm{~cm}$ (min-max: 80-160) for CP, and 140.36 $\pm 24.35 \mathrm{~cm}$ (min-max: 100-185) for controls. The children's mean weight was $17.79 \pm 5.93 \mathrm{~kg}$ (min-max: 8-30) for SB, $38.77 \pm 19.05 \mathrm{~kg}$ (min-max: 12-70) for MD, $18.46 \pm 8.91 \mathrm{~kg}$ (min-max: 8-35) for DS, $27.61 \pm 15.33 \mathrm{~kg}$ (min-max: 10-60) for CP, and $42.54 \pm 20.26 \mathrm{~kg}$ (min-max: 16-85) for controls. When the diagnostic groups were compared in terms of age ( $p<0.001)$, height $(p<0.001)$, and weight $(p<0.001)$, significant differences were found between groups $(p<0.05)$ : SB-control $(p<0.001)$, MD-control $(p<0.001)$, DS-control $(p<0.001)$, CP-control $(p<0.001)$. When the inter-group differences were compared binarily with the diagnostic groups in terms of mean age, there was a significant difference between SB and MD $(p<0.001)$, SB and controls $(p=0.002)$, MD and DS $(p<0.001)$, and DS and controls $(p<0.001)$. When all the groups were compared in terms of height, significant differences were observed between SB and MD $(p<$ $0.001)$, SB and controls $(p<0.001)$, MD and DS $(p<0.001)$, and DS and controls $(p<0.001)$. When all the groups were compared in terms of mean weight, significant differences were revealed between SB and MD $(p<0.001)$, SB and controls $(p<0.001)$, MD and DS $(p=0.002)$, and DS and controls $(p<0.001)$ (Table 1).

The income levels of the groups were: low in $64.8 \%(n=$ 59), medium in $20.9 \%(n=19)$, high in $14.3 \%(n=13)$. The status of existing health problems among the parents was affirmative in $37.4 \%(n=34)$ and negative in $62.6 \%(n=57)$. The employed parents were only fathers in $78 \%(n=71)$ and both parents in $22 \%(n=20)$. Regarding the children's treat- 
Table 1. Comparison of groups in terms of age, height, and weight (one-way ANOVA)

\begin{tabular}{|c|c|c|c|c|c|c|c|}
\hline Characteristics & $\begin{array}{c}\mathrm{SB}(1) \\
\text { Mean } \pm S D \\
(\min -\max )\end{array}$ & $\begin{array}{c}\text { MD (2) } \\
\text { Mean } \pm S D \\
(\min -\max )\end{array}$ & $\begin{array}{c}\text { DS (3) } \\
\text { Mean } \pm S D \\
(\min -\max )\end{array}$ & $\begin{array}{c}\text { CP (4) } \\
\text { Mean } \pm S D \\
(\min -\max )\end{array}$ & $\begin{array}{l}\text { Controls (5) } \\
\text { Mean } \pm S D \\
(\min -\max )\end{array}$ & $\begin{array}{l}\text { Between- } \\
\text { group } p\end{array}$ & $\begin{array}{l}\text { Post-hoc tests } \\
\qquad p<0.05\end{array}$ \\
\hline Age (years) & $\begin{array}{c}6.47 \pm 2.47 \\
(4-12)\end{array}$ & $\begin{array}{c}11.69 \pm 4.96 \\
(4-20)\end{array}$ & $\begin{array}{c}5.87 \pm 2.44 \\
(2-10)\end{array}$ & $\begin{array}{c}8.83 \pm 4.25 \\
(4-18)\end{array}$ & $\begin{array}{c}11.31 \pm 4.28 \\
(5-18)\end{array}$ & $<0.001^{*}$ & $1: 2 ; 1: 5 ; 2: 3 ; 3: 5$ \\
\hline Height (cm) & $\begin{array}{c}103.58 \pm 13.44 \\
(80-135)\end{array}$ & $\begin{array}{c}136.05 \pm 25.02 \\
(98-170)\end{array}$ & $\begin{array}{c}101.75 \pm 22.69 \\
(55-130)\end{array}$ & $\begin{array}{c}122.94 \pm 19.93 \\
(80-160)\end{array}$ & $\begin{array}{c}140.36 \pm 24.35 \\
(100-185)\end{array}$ & $<0.001^{*}$ & $1: 2 ; 1: 5 ; 2: 3 ; 3: 5$ \\
\hline Weight (kg) & $\begin{array}{c}17.79 \pm 5.93 \\
(8-30)\end{array}$ & $\begin{array}{c}38.77 \pm 19.05 \\
(12-70)\end{array}$ & $\begin{array}{c}18.46 \pm 8.91 \\
(8-35)\end{array}$ & $\begin{array}{c}27.61 \pm 15.33 \\
(10-60)\end{array}$ & $\begin{array}{c}42.54 \pm 20.26 \\
(16-85)\end{array}$ & $<0.001^{*}$ & $1: 2 ; 1: 5 ; 2: 3 ; 3: 5$ \\
\hline
\end{tabular}

SB - spina bifida, MD - muscular dystrophy, DS - Down syndrome, CP - cerebral palsy

* post-hoc Tukey's test, $p<0.05$

ments, 22\% $(n=20)$ received physiotherapy, $1.1 \%(n=1)$ received surgical treatment, $1.1 \%(n=1)$ received orthosis treatment, $25.3 \%(n=23)$ received both physiotherapy and individual training, $16.5 \%(n=15)$ received physiotherapy, individual training, and surgery, and $9.9 \%(n=9)$ received all of them.

A significant difference was found for IPFAM total $(p<$ $0.001)$ and PEDI functional skills $(p<0.001)$ scores between all groups (Table 2). A significant difference was observed in IPFAM total scores between the parents of the disabled children and controls $(p<0.001)$. There was also a significant difference in PEDI functional skills between SB and MD $(p=$ $0.03)$, between DS and controls ( $p<0.001)$, and between CP and controls $(p<0.001)$ (Table 2$)$.

There were significant differences in WeeFIM self-care $(p<0.001)$, sphincter control $(p<0.001)$, mobility $(p<0.001)$, locomotion $(p<0.001)$, communication $(p<0.001)$, and total $(p<0.001)$ scores, as well as in NHP social isolation $(p=0.01)$ and physical activity $(p=0.03)$ parameters (Tables 3,4$)$. In the pairwise comparison of all groups and controls in terms of WeeFIM and quality of life, significant differences were found in favour of MD in WeeFIM sphincter control between SB and MD patients $(p<0.001)$. A significant difference was observed in favour of SB in WeeFIM locomotion $(p<0.001)$ and NHP social isolation $(p=0.002)$ parameters. In the comparison of SB and controls, significant differences were revealed in favour of controls in WeeFIM self-care $(p<0.001)$, sphincter control $(p<0.001)$, locomotion $(p<0.001)$, mobility $(p<0.001)$, and social cognition $(p=0.01)$ parameters, as well as in the total score of WeeFIM $(p<0.001)$. When we compared MD and DS in terms of WeeFIM sphincter control, communication, and social cognition, significant differences were indicated in favour of MD $(p<0.005)$. There was a significant difference between MD and CP in favour of MD in terms of the WeeFIM social cognition parameter $(p<0.001)$. For the WeeFIM self-care, mobility, locomotion, and total scores, there were significant differences between MD and controls in favour of controls. There was a significant difference between DS and controls in favour of controls in terms of WeeFIM self-care $(p<0.001)$, sphincter control $(p<0.001)$, mobility $(p<0.001)$, communication $(p<0.001)$, and locomotion $(p<0.001)$ parameters, as well as in the total score $(p<0.001)$. In terms of the WeeFIM self-care $(p<0.001)$, sphincter control $(p<0.001)$, mobility $(p<0.001)$, locomotion $(p<0.001)$, communication $(p=0.003)$, social cognition $(p<0.001)$, and total $(p<0.001)$ scores, significant differences were noted between CP and controls in favour of controls.

Table 2. Comparison of the parents of the control group and those of the disabled children in terms of IPFAM, STAI-I, STAI-II, and PEDI functional skills scores

\begin{tabular}{|c|c|c|c|c|}
\hline Group & $\begin{array}{c}\text { IPFAM } \\
\text { Mean } \pm S D \\
(\min -\max )\end{array}$ & $\begin{array}{c}\text { STAI-I } \\
\text { Mean } \pm S D \\
(\text { min-max })\end{array}$ & $\begin{array}{c}\text { STAI-II } \\
\text { Mean } \pm S D \\
(\min -\max )\end{array}$ & $\begin{array}{l}\text { PEDI functional skills } \\
\text { Mean } \pm S D \\
\text { (min-max) }\end{array}$ \\
\hline $\mathrm{SB}(n=17)$ & $\begin{array}{c}45.17 \pm 11.01 \\
(22-60)\end{array}$ & $\begin{array}{c}42.23 \pm 7.40 \\
(30-52)\end{array}$ & $\begin{array}{c}49.94 \pm 10.67 \\
(35-67)\end{array}$ & $\begin{array}{c}105.70 \pm 47.10 \\
(34-196)\end{array}$ \\
\hline $\mathrm{MD}(n=18)$ & $\begin{array}{c}51 \pm 15.16 \\
(25-88)\end{array}$ & $\begin{array}{c}44 \pm 14.92 \\
(24-70)\end{array}$ & $\begin{array}{c}44.33 \pm 11.80 \\
(30-72)\end{array}$ & $\begin{array}{c}152.22 \pm 44.91 \\
(72-197)\end{array}$ \\
\hline $\mathrm{DS}(n=16)$ & $\begin{array}{c}49.56 \pm 8.96 \\
(33-60)\end{array}$ & $\begin{array}{c}42.43 \pm 14.07 \\
(23-74)\end{array}$ & $\begin{array}{c}45.68 \pm 9.34 \\
(33-64)\end{array}$ & $\begin{array}{c}84.06 \pm 47.23 \\
(4-188)\end{array}$ \\
\hline $\mathrm{CP}(n=18)$ & $\begin{array}{c}51.94 \pm 10.33 \\
(32-70)\end{array}$ & $\begin{array}{c}45.16 \pm 9.26 \\
(27-61)\end{array}$ & $\begin{array}{c}47.61 \pm 7.68 \\
(31-58)\end{array}$ & $\begin{array}{c}94.55 \pm 66.01 \\
(2-194)\end{array}$ \\
\hline $\begin{array}{l}\text { Control } \\
(n=22)\end{array}$ & $\begin{array}{c}85.31 \pm 18.11 \\
(50-96)\end{array}$ & $\begin{array}{c}39.40 \pm 15.41 \\
(21-68)\end{array}$ & $\begin{array}{c}41.27 \pm 12.63 \\
(25-69)\end{array}$ & $\begin{array}{c}190.40 \pm 17.29 \\
(124-197)\end{array}$ \\
\hline $\begin{array}{l}\text { Total } \\
(n=91)\end{array}$ & $\begin{array}{c}58.14 \pm 20.45 \\
(22-96)\end{array}$ & $\begin{array}{c}42.51 \pm 12.67 \\
(21-74)\end{array}$ & $\begin{array}{c}45.52 \pm 10.89 \\
(25-72)\end{array}$ & $\begin{array}{c}129.37 \pm 61.39 \\
(2-197)\end{array}$ \\
\hline$p$ & $<0.001^{*}$ & 0.674 & 0.133 & $\leq 0.001^{*}$ \\
\hline
\end{tabular}

IPFAM - Impact on Family Scale, STAI-I - State Anxiety Inventory, STAI-II - Trait Anxiety Inventory, PEDI - Pediatric Evaluation of Disability Inventory, SB - spina bifida, MD - muscular dystrophy, DS - Down syndrome, CP - cerebral palsy

* one-way ANOVA, $p \leq 0.001$; IPFAM: SB-control $(p<0.001)$, MD-control $(p<0.001)$, DS-control $(p<0.001)$, CP-control $(p<0.001)$;

PEDI functional skills: SB-MD $(p=0.030)$, SB-control $(p<0.001)$, MD-DS $(p<0.001), \operatorname{MD}-\mathrm{CP}(p=0.003)$, MD-SB $(p=0.03)$,

DS-control $(p<0.001)$, CP-control $(p<0.001)$ 
Table 3. Comparison of NHP scores in the diagnostic groups and controls

\begin{tabular}{|c|c|c|c|c|c|c|c|}
\hline Group & $\begin{array}{c}\text { NHP energy } \\
\text { Median (min-max) }\end{array}$ & $\begin{array}{c}\text { NHP pain } \\
\text { Median (min-max) }\end{array}$ & $\begin{array}{l}\text { NHP emotional } \\
\text { reactions } \\
\text { Median (min-max) }\end{array}$ & $\begin{array}{c}\text { NHP sleep } \\
\text { Median (min-max) }\end{array}$ & $\begin{array}{c}\text { NHP social } \\
\text { isolation } \\
\text { Median (min-max) }\end{array}$ & $\begin{array}{c}\text { NHP physical } \\
\text { activity } \\
\text { Median (min-max) }\end{array}$ & $\begin{array}{c}\text { NHP total } \\
\text { Median (min-max) }\end{array}$ \\
\hline MD & $60.80(0-122)$ & $23.94(0-100)$ & $28.60(0-100)$ & $22.38(0-100)$ & $0(0-100)$ & $43.90(0-100)$ & $173.60(0-600)$ \\
\hline DS & $30.60(0-100)$ & $10.09(0-100)$ & $10.47(0-100)$ & $19.91(0-100)$ & $0(0-61.5)$ & $0(0-58.83)$ & $91.54(0-472.29)$ \\
\hline $\mathrm{CP}$ & $63.20(0-100)$ & $12.91(0-100)$ & $27.49(0-86.05)$ & $12.57(0-77.68)$ & $35.33(0-77.99)$ & $11.20(0-67.16)$ & $151.90(0-447.74)$ \\
\hline Control & $38(0-100)$ & $7.91(0-100)$ & $10.11(0-100)$ & $28.67(0-77.63)$ & $0(0-100)$ & $5.39(0-53.40)$ & $71.9(0-489.14)$ \\
\hline Total $(n=91)$ & $60.80(0-122)$ & $18.74(0-100)$ & $24.46(0-100)$ & $27.26(0-100)$ & $0(0-100)$ & $11.20(0-100)$ & $167.96(0-600)$ \\
\hline$p$ & 0.189 & 0.598 & & 0.642 & $0.018^{*}$ & $0.038^{*}$ & 0.169 \\
\hline
\end{tabular}

NHP - Nottingham Health Profile, SB - spina bifida, MD - muscular dystrophy, DS - Down syndrome, CP - cerebral palsy

${ }^{*}$ Kruskal-Wallis test, $p<0.05$; SB-DS: NHP social isolation $(p=0.002)$; Mann-Whitney $U$ test, Bonferroni, $p<0.005$

Table 4. Comparison of WeeFIM scores in the diagnostic groups and controls

\begin{tabular}{|l|c|c|c|c|c|}
\hline Group & $\begin{array}{c}\text { WeeFIM self-care } \\
\text { Median (min-max) }\end{array}$ & $\begin{array}{c}\text { WeeFIM sphincter } \\
\text { control } \\
\text { Median (min-max) }\end{array}$ & $\begin{array}{c}\text { WeeFIM mobility } \\
\text { Median (min-max) }\end{array}$ & $\begin{array}{c}\text { WeeFIM locomotion } \\
\text { Median (min-max) }\end{array}$ & $\begin{array}{c}\text { WeeFIM } \\
\text { communication } \\
\text { Median (min-max) }\end{array}$ \\
\hline SB & $15(6-42)$ & $2(2-14)$ & $6(2-21)$ & $2(2-14)$ & $14(4-14)$ \\
\hline MD & $27(6-48)$ & $14(2-42)$ & $13(3-21)$ & $8(2-21)$ & $14(2-14)$ \\
\hline DS & $13(6-24)$ & $3(2-14)$ & $10.5(1-20)$ & $8(2-14)$ & $8(3-14)$ \\
\hline CP & $14.50(6-45)$ & $4(2-14)$ & $7.5(3-22)$ & $4.5(2-14)$ & $10.5(2-14)$ \\
\hline Control & $56(22-63)$ & $14(2-14)$ & $35(9-35)$ & $28(18-35)$ & $14(11-14)$ \\
\hline Total $(n=91)$ & $20(6-63)$ & $6(2-42)$ & $12(1-35)$ & $8(2-35)$ & $14(2-14)$ \\
\hline$p$ & $\leq 0.001^{*}$ & $\leq 0.001^{*}$ & $\leq 0.001^{*}$ & $\leq 0.001^{*}$ & $\leq 0.001^{*}$ \\
\hline
\end{tabular}

WeeFIM - Functional Independence Measure for Children, SB - spina bifida, MD - muscular dystrophy, DS - Down syndrome, $\mathrm{CP}$ - cerebral palsy

* Kruskal-Wallis test, $p<0.05$; SB-MD: WeeFIM sphincter control $(p<0.001)$; SB-DS: WeeFIM locomotion $(p<0.001)$; SB-control: WeeFIM self-care $(p<0.001)$, WeeFIM sphincter control $(p<0.001)$, WeeFIM mobility $(p<0.001)$, WeeFIM locomotion $(p<0.001)$, WeeFIM social cognition $(p=0.004)$, WeeFIM total $(p<0.001)$; MD-DS: WeeFIM sphincter control $(p<0.001)$, WeeFIM communication $(p=0.002)$, WeeFIM social cognition $(p<0.001)$; MD-CP: WeeFIM social cognition $(p=0.003)$; MD-control: WeeFIM self-care $(p<0.001)$, WeeFIM mobility $(p<0.001)$, WeeFIM locomotion $(p<0.001)$, WeeFIM total $(p<0.001)$; DS-control: WeeFIM self-care $(p<0.001)$, WeeFIM sphincter control $(p<0.001)$, WeeFIM mobility $(p<0.001)$, WeeFIM locomotion $(p<0.001)$, WeeFIM communication $(p<0.001)$, WeeFIM social cognition $(p<0.001)$, WeeFIM total $(p<0.001)$; CP-control: WeeFIM self-care $(p<0.001)$, WeeFIM sphincter control $(p<0.001)$, WeeFIM mobility $(p<0.001)$, WeeFIM locomotion $(p<0.001)$, WeeFIM communication $(p<0.001)$, WeeFIM social cognition $(p<0.001)$, WeeFIM total $(p<0.001)$; Mann-Whitney $U$ test, Bonferroni, $p<0.005$

Table 5. Relationship between the total disease duration and the mean IPFAM, STAI-I, and STAI-II scores of the parents (Pearson)

\begin{tabular}{|l|c|c|c|}
\hline Scale & $\begin{array}{c}\text { Total disease } \\
\text { duration (years) } \\
\text { Mean } \pm S D\end{array}$ & $p$ & $r$ \\
\hline IPFAM (mean $\pm S D$ ) & $58.14 \pm 20.45$ & $<0.001^{*}$ & $-0.622^{\star}$ \\
\hline STAI-I (mean $\pm S D$ ) & $42.51 \pm 12.67$ & $0.010^{*}$ & $0.269^{\star}$ \\
\hline STAI-II (mean $\pm S D$ ) & $45.52 \pm 10.89$ & 0.059 & 0.199 \\
\hline
\end{tabular}

IPFAM - Impact on Family Scale, STAI-I - State Anxiety Inventory,

STAI-II - Trait Anxiety Inventory

* Pearson correlation, $p<0.05$
Table 6. Relationship between the total disease duration and NHP scores of the parents (Spearman)

\begin{tabular}{|l|c|c|}
\hline \multirow{2}{*}{ NHP sub-parameters } & \multicolumn{2}{|c|}{$\begin{array}{c}\text { Total disease duration (years) } \\
\text { (mean } \pm S D) ; 5.71 \pm 4.48\end{array}$} \\
\cline { 2 - 3 } & $p$ & $r$ \\
\hline Energy & 0.07 & 0.186 \\
\hline Pain & 0.36 & 0.096 \\
\hline Emotional reactions & 0.30 & 0.109 \\
\hline Sleep & 0.71 & -0.038 \\
\hline Social isolation & 0.25 & 0.121 \\
\hline Physical activity & 0.02 & $0.232^{*}$ \\
\hline Total & 0.21 & 0.130 \\
\hline
\end{tabular}

NHP - Nottingham Health Profile

* Spearman correlation, $p<0.05$ 
There was a strong negative correlation between disease duration and the mean IPFAM score in parents $(p<0.001$, $r=-0.622$ ). A strong positive correlation was found between the mean STAI-I score and disease duration $(p<0.001, r=$ 0.269 ). No correlation was observed between the mean STAI-II score and disease duration $(p<0.05)$ (Table 5).

When the relationship between total disease duration and quality of life parameters was examined, a positive correlation was revealed only between the physical activity sub-parameter and disease duration $(p=0.02, r=0.232)$ (Table 6).

\section{Discussion}

There exist few studies investigating the impact of different disability groups on families [9]. This study presented that the severity of the impact on families did not depend on the disability type. However, it was observed that disability affected the families of disabled children compared with families with healthy children. In addition, it was shown that the functional skills of the disabled children were negatively changed by their disability type in comparison with their healthy peers. Health-related quality of life of the families was found to be influenced by the independence level of the children in daily living activities. Locomotion levels affected the social isolation parameter of quality of life, especially in patients with SB and DS. The anxiety levels of the families did not change with the type of disability.

When the mean age, height, and weight of the groups were compared in accordance with the diagnosis groups, significant differences were found between groups. There was a significant difference in the mean weight of the patients between SB and MD, SB and controls, MD and DS, and DS and controls. This difference may be due to the high mean age of the individuals with MD and controls.

In a study conducted by Simşek et al. [9] involving parents of different physically and mentally disabled children, it was shown that the severity of the impact on the family could be affected by family education level and children's mental retardation level. In this study, family education levels were mostly low. In another study, in which the activity and participation level of children with CP was investigated, about $50 \%$ of the parents were primary school graduates [13]. Similarly, most parents in the present study exhibited low educational level. When the income distribution in the groups was examined, the economic levels of the parents turned out low in $64.8 \%$, medium in $20.9 \%$, and high in $14.3 \%$. These results are consistent with the literature [3]. To reduce the severity of impact on families with low sociocultural levels, governments should develop various social state policies that will reduce this burden, and psychosocial support should be provided to increase the children's independence level through various trainings so that they can discover their potentials.

It was observed in the present study that the parents of the physically disabled children were more affected by the disease process than the healthy controls. This implies that the effect levels in the families did not change with the disability type. In addition, although functional levels and mental involvements may vary among disabled groups, families showed similarities in the severity of impact. There was a mental disability, especially in individuals with DS, but it did not influence the family impact levels. In another study, family impact levels involving children with DS or other mental disability groups were examined, and it was observed that the family impact scores of the caregivers of DS children were higher. However, only communication and family relations scores of the family impact scale were found to be significantly higher as compared with the other subscales [14]. This result differs from the outcomes of our study. However, this difference is considered to result from the fact that the sample consisted of different mental disability groups, such as learning difficulty and autism. In addition, in our study, with increasing total duration of the disease, the severity of impact on the family decreased. This is thought to be because families accept the disease with time.

Although the difficulties experienced by children with different disabilities may vary, this does not change the level of anxiety experienced by families. In the literature, it is emphasized that stress, anxiety, and depression levels are generally high among parents of children with CP [6]. In a study examining anxiety, depression, and quality of life of parents of children with neuromuscular diseases, mothers' general anxiety levels were high. These were found to be related to the severity of depression, age, education level, time spent with the child, and the independence level of the children in daily life [15]. In a previous study, quality of life and impact levels among caregivers of children with meningomyelocele were investigated in relation to anxiety and depression levels [15]. Although the anxiety and depression levels of the parents were not high, anxiety levels were reported to be correlated with quality of life and impact on families. Anxiety levels were correlated with the physical function, physical pain, social function, and mental health dimensions of quality of life. It has been shown that there is a relationship between anxiety levels and general scores of families' general strain, isolation, frustration, environmental dimensions, and burden levels [16]. In a meta-analysis study comparing family stress levels of various disability groups, it was concluded that parents of children with autism had higher stress levels than parents of children with DS, CP, or other mental disability [17]. In our study, it was observed that state anxiety levels of the parents were negatively affected only when disease duration increased. As the disease lasts longer, parents may be more concerned about their children's independence. This is thought to be because the general population of the study consists of individuals with physical disabilities. Parental health-related quality of life was found to be adversely affected by increasing illness duration. It is important to establish support programs so that anxiety in parents would result in minimal loss of health-related quality of life. Parents should be provided with training including information, care, and psychosocial support to reduce physical burdens.

Functional skills of children with MD were found to be better than those of children with SB, DS, or CP. The control group exhibited better functional skills than MD. This may be because children with MD were at an age in which mobility had not yet been completely lost. Topuz et al. [1] examined differences in health-related quality of life, social function, and personal care levels of different disability groups. They reported significant differences between the functional skills of individuals with $\mathrm{CP}$, hearing impairment, and mental retardation, which agrees with our results. It was found that individuals with CP had more difficulty in functional skills such as selfcare and mobility [1]. In our study, in terms of functional skills, there was a difference between children with $\mathrm{CP}$ and MD, and $\mathrm{CP}$ and controls. This implies that individuals with $\mathrm{CP}$ are the most challenged group in functional skills. Therefore, it may be considered to make necessary modifications in daily life and to provide ergotherapy support in accordance with the patients' needs to increase their functional skills.

Simşek et al. [9] reported that the severity of impact on the families of different physically and mentally handicapped children was affected by the independence levels of the chil- 
dren in daily life. Similarly, in our study, a correlation was found between the independence level and the severity of impact on the family. It was concluded that the sphincter control skills of patients with MD were better than in patients with $\mathrm{SB}$. This is due to insufficient or no sphincter innervation in patients with SB. It was also observed that the MD group had higher sphincter control, communication, and social cognition scores than DS. It was suggested that this was due to the mental involvement in the DS group. The control group's independence level in daily living activities was better compared with MD, DS, and CP patients. Owing to the lack of similar studies, we believe that these results will contribute to the literature in terms of revealing the independence levels of children with different physical disabilities.

Parents of children with MD were more affected in physical activity parameters, which was probably because these children had higher mean weight and age. It was emphasized in a review that the parents' quality of life was not sufficiently addressed compared with the care provided to the children with CP [6]. In addition, it was stated that the quality of life of CP children's parents was lower than that of healthy children's parents, which is in line with our study. In the same study, the quality of life of the families was found to be related to the rough motor skills of the children. However, it was underscored that there was no difference in mothers' quality of life except in the pain parameter before and after rehabilitation. In this study, the authors maintained that caring for a child with CP might positively affect parents' establishing new social networks. However, it was also argued that it might have negative effects on the parents' physical health, social relations, freedom and independence, family relations, and financial situation [6]. Accessibility in all areas should be increased in order to prevent the social isolation of families and integrate them into the society. In addition, it may be considered that leisure activities or institutional health support programs with various groups may be offered during the education process.

A study conducted by Türkoğlu et al. [18] involved children with CP. Anxiety and depression symptoms of the mothers were shown to have significant determinant effects on their quality of life. The lack of assessment of the effects of anxiety levels on quality of life is a limitation of our study. Tekinarslan [19] investigated depression and quality of life of parents of children with autism, DS, or CP in a Turkish population. He reported that the quality of life of $\mathrm{CP}$ children's parents was lower compared with DS. In addition, in the same study, it was observed that the quality of life increased with decreasing severity of depression, which is consistent with our results regarding the relationship between family anxiety levels and health-related quality of life. Yılmaz et al. [15] indicated that the health-related quality of life of mothers of children with neuromuscular diseases had a positive relationship with the time spent with the child, educational level, and severity of depression. It was found that the quality of life decreased with increasing levels of the children's independence, which is consistent with our study. Valença et al. [17] examined parents of children with meningomyelocele and observed that parents with primary education had lower health-related quality of life, which corroborates our results. Quality of life was found to be associated with depression levels. Low socioeconomic level of the families was considered to have an effect on the quality of life and the severity of impact on the families. It was revealed that as the total disease duration increased, only the physical activity parameter increased in the quality of life of the parents. This suggests that as the age, height, and weight of the physically disabled children increase, the family's strain level is adversely affected.
Chien and Lee [20] reported that most of the parents perceived social support as insufficient regarding family support services and child care. In addition, parents stated that they needed information about their children's diseases and treatments. They emphasized that it might be difficult to develop effective parenting strategies if the parents could not obtain information from health experts, teachers, or other parents. Tehee et al. [21] highlighted that stress and failure to cope might be related to the shortage of governmental institutions supporting parents. Inadequate support from all services and difficulties in accessing finance for their children may increase the level of stress in the parents of children with disabilities and reduce their health-related quality of life. This may make it difficult to cope with difficulties using the strategies of caring for children with disabilities. For this reason, parents' education and psychosocial support should be included in the rehabilitation services. In this way, families can develop more accurate coping strategies.

\section{Limitations}

It is a limitation of our study that the relationship between the health-related quality of life and anxiety levels of the disabled children's parents was not examined in the context of their functional levels. Further studies are needed to investigate the quality of life and anxiety levels of the families in relation with their functional levels.

\section{Conclusions}

In this study, it was shown that, in addition to the physiotherapy applied in rehabilitation centres to physically disabled individuals, the social needs of the caregivers should also be identified because a successful rehabilitation program can only be carried out with the work of a multidisciplinary team involving both the child and the family. Further studies are needed to investigate the effects of caring for disabled individuals on parents' functionality and welfare. In previous studies, in addition to the lack of the control group, study groups were heterogeneously distributed, e.g. in terms of age. Although similar assessment tools were used for some variables, the measurements applied were different, which makes it difficult to compare their results. Further research is needed to investigate the effect of caregivers' personal characteristics (self-efficacy, self-esteem, or coping strategies) on welfare levels. As a result, it will be easier to develop different strategies that can improve families' quality of life.

\section{Acknowledgements}

The authors are grateful to the parents and children who took their time to participate in this study. The authors also thank Osman Topac for English review.

\section{Disclosure statement}

No author has any financial interest or received any financial benefit from this research.

\section{Conflict of interest}

The authors state no conflict of interest.

\section{References}

1. Topuz S, Ülger Ö, Elbasan B, Yakut H, Ayhan Y. Investigation of the quality of life and psychosocial support needs of the mothers having children with different disabilities in Turkey: a pilot study [in Turkish]. Turk J Physiother Rehabil. 2014;25(2):63-71; doi: 10.7603/s40680 -014-0009-6. 
2. Goudie A, Havercamp S, Jamieson B, Sahr T. Assessing functional impairment in siblings living with children with disability. Pediatrics. 2013;132(2):e476-e483; doi: 10.1542/peds.2013-0644.

3. Isa SNI, Ishak I, Rahman AA, Saat NZM, Din NC, Lubis SH, et al. Health and quality of life among the caregivers of children with disabilities: a review of literature. Asian J Psychiatr. 2016;23:71-77; doi: 10.1016/j.ajp.2016.07.007.

4. Tarakci D, Yeldan I, Zengin A, Tekeoglu A, Kostanoglu A, Kuru T, et al. Comparison of the effect of low back pain on their daily life activities in sedentary women and mothers with physically handicapped children [in Turkish]. Nobel Med. 2010;6(3):62-65.

5. Yildiz A, Tarakci D, Hajebrahimi F, Mutluay F. Disabled children's functionality and maternal quality of life and psychological status. Pediatr Int. 2016;58(12):1291-1296; doi: 10.1111/ped.13020.

6. Pousada M, Guillamón N, Hernández-Encuentra E, Muñoz E, Redolar D, Boixadós M, et al. Impact of caring for a child with cerebral palsy on the quality of life of parents: a systematic review of the literature. J Dev Phys Disabil. 2013;25(5):545-577; doi: 10.1007/s10882-013-9332-6.

7. Feizi A, Najmi B, Salesi A, Chorami M, Hoveidafar R. Parenting stress among mothers of children with different physical, mental, and psychological problems. J Res Med Sci. 2014;19(2):145-152.

8. Tsai S-M, Wang $\mathrm{H}-\mathrm{H}$. The relationship between caregiver's strain and social support among mothers with intellectually disabled children. J Clin Nurs. 2009;18(4): 539-548; doi: 10.1111/j.1365-2702.2008.02524.x.

9. Simşek IE, Erel S, Simşek TT, Uysal SA, Yakut H, Yakut Y, et al. Factors related to the impact of chronically disabled children on their families. Pediatr Neurol. 2014;50(3): 255-261; doi: 10.1016/j.pediatrneurol.2013.11.012.

10. Akdağ M, Bysal ZY, Atli A, Samanci B, Topcu I. A multicentric prospective study: anxiety and associated factors among parents of children undergoing mild surgery in ENT. J Clin Exp Invest. 2014;5(2):206-210; doi: 10.5799/ ahinjs.01.2014.02.0390.

11. Yildiz N, Topuz O, Gungen GO, Deniz S, Alkan H, Ardic F. Health-related quality of life (Nottingham Health Profile) in knee osteoarthritis: correlation with clinical variables and self-reported disability. Rheumatol Int. 2010;30(12): 1595-1600; doi: 10.1007/s00296-009-1195-x.

12. Erkin G, Elhan AH, Aybay C, Sirzai H, Ozel S. Validity and reliability of the Turkish translation of the Pediatric Evaluation of Disability Inventory (PEDI). Disabil Rehabil. 2007;29(16):1271-1279; doi: 10.1080/0963828060096 4307.

13. Büğüşan $S$, Kahraman $A$, Elbasan $B$, Mutlu A. Do adolescents with cerebral palsy agree with their caregivers on their participation and quality of life? Disabil Health J. 2018;11(2):287-292; doi: 10.1016/j.dhjo.2017.10.009.

14. Isa SNI, Ishak I, Rahman A, Saat N, Din N, Lubis S, et al. Sociodemographics, disability factors and family impact between children with Down syndrome and other children with disabilities in Kelantan, Malaysia. Int J Manag Appl Sci. 2016;2(4):32-37.

15. Yilmaz TO, Yildirim SA, Kizildoğan ET, Kilinç M, Özer S. Comparison of depression, anxiety, and health related quality of life levels of parents of children with neuromuscular diseases. Turk J Physiother Rehabil. 2013;24(1): 54-63.

16. Valença AM, de Menezes TA, Calado AA, de Aguiar Cavalcanti G. Burden and quality of life among caregivers of children and adolescents with meningomyelocele: mea- suring the relationship to anxiety and depression. Spinal Cord. 2012;50(7):553-557; doi: 10.1038/sc.2012.10.

17. Hayes SA, Watson SL. The impact of parenting stress: a meta-analysis of studies comparing the experience of parenting stress in parents of children with and without autism spectrum disorder. J Autism Dev Disord. 2013; 43(3):629-642; doi: 10.1007/s10803-012-1604-y.

18. Türkoğlu S, Bilgiç A, Türkoğlu G, Yilmaz S. Impact of symptoms of maternal anxiety and depression on quality of life of children with cerebral palsy. Noro Psikiyatr Ars. 2016;53(1):49-54; doi: 10.5152/npa.2015.10132.

19. Tekinarslan IC. A comparison study of depression and quality of life in Turkish mothers of children with Down syndrome, cerebral palsy, and autism spectrum disorder. Psychol Rep. 2013;112(1):266-287; doi: 10.2466/21. 02.15.PR0.112.1.266-287.

20. Chien W-T, Lee IYM. An exploratory study of parents' perceived educational needs for parenting a child with learning disabilities. Asian Nurs Res (Korean Soc Nurs Sci). 2013;7(1):16-25; doi: 10.1016/j.anr.2013.01.003.

21. Tehee E, Honan R, Hevey D. Factors contributing to stress in parents of individuals with autistic spectrum disorders. J Appl Res Intellect Disabil. 2009;22(1):34-42; doi: 10.1111/j.1468-3148.2008.00437.x. 